\title{
Moral Issues in Environmental Crisis: A Feminists Approach
}

\author{
Laimayum Bishwanath Sharma*
}

\begin{abstract}
Environmental crisis is one of the biggest problems of the world that involves moral issues. From different perspectives the crisis can be analyzed in order to find out a solution. This paper intends to highlight on feminists ethical theory with the aim of clarifying the standpoints of eco-feminism on the issues of environmental ethics. An attempt has been made to initiate a discussion about the issue of how environmental degradation and exploitation of nature became a feminist issue. The feminists' view on the relationship between women and nature has engaged with the debates in environmental ethics and politics, and has, at the same time, developed a counter argument against the domination over women and nature by manfolk as a political activism.
\end{abstract}

The contribution of women in resolving the issues relating to the environmental degradation is worth mentioning. It is observed more clearly in the women's movement over the last few decades. It develops a new field of philosophical inquiry known as 'ecofeminism'. Eco-feminism is a social movement. It is a movement of women to protect natural processes. The feminists' discussion on the environmental crisis draws on the idea of a principle of sustainable livelihood as human developmental scheme. They challenge the Eurocentric cultural construction of artificial

\footnotetext{
*Assistant Professor, Department of Philosophy, Manipur University, Imphal
} 
conceptual dualisms such as feminine versus masculine, nature versus culture. Eco-feminists, like Mies, Shiva and Merchant (1993, 1996), consider this movement grows as an outcome of women's experiences in everyday life. It is also said that their objective is global, whereas conventional feminism tends to be inward looking.

The term eco-feminism was first used to illustrate the potential of women for bringing about an ecological revolution as a philosophical and political movement, in which human beings share the world with all creatures and living things. Eco-feminists make a synthesis of environmentalism and feminism on the theme of dominance of men over women and humanity over nature. It asserts a theoretical, practical and ethical implication on the subjugation of women and nature as outlines of the eco-feminist principle and ethical theory.

This paper intends to locate the conceptual foundation of ecofeminism towards the ecological concerns. Further examines the question of environmental degradation and exploitation of nature as feminist issue in the eco-feminism movement. It is to assess the concept of eco-feminism extends to the framework for a discussion particularly the issue of environmental ethics.

Eco-feminists trace the roots of the ecological crisis right from dualistic thinking that arose in classical Greece. Plato wrote that reason enables man to rise above the body and nature in order to understand the eternal and unchanging truth. Platonic dualism not only dichotomise between mind and matter, spirit and nature, soul and body, reason and emotion, but also assumed that mind, spirit, soul, and reason should rule over matter, nature, body and emotion. As feminists have argued, Platonic dualism identified men with mind, spirit, soul and reason, while women with matter, nature, body and emotion. Thus, it seemed logical that man should rule over women and nature (Griffin, 1978).

Modern science is built up on the foundations of the dualism of spirit/reason and matter. While in principle the capacity for human reason might have been attributed equally to women and men, in 
fact modern thinkers and scientists collude in the fiction that women's reason is deficient. Thus one of the critical insights of modernity - 'the rights of man' was initially denied to women and other races. This sexism and racism attitude inherent in the socalled 'rational' men, it was impossible for them to perceive that they had anything to learn from the so-called 'irrational' women and 'pre-rational' and primitive people. Modern feminism radically asserts that the rights of men should be extended to women. Women are fully as capable of rational thinking as men. They opine that the divorce of reason and emotion is the characteristic of western philosophy and scientific traditions. They believe that the best and deepest thinking is 'embodied thinking' that combines reason and emotion (Christ, 1998). Feminists criticize dualistic thinking of identifying women with the body and nature but not with the spirit and reason. In asserting female intelligence, women are just as capable as men of 'rising above' the 'limitations' of the body and nature (Ortner, 1974).

Eco-feminists generally agree that "there are important interconnections among the unjustified domination over women and the unjustified domination over nature" and that reveals the relationships among these 'isms of domination' is necessary in order to develop both adequate feminist theories and practices and adequate environmental theories and practices (Pierce, Nelson and Warren, 2002, 63).

Eco-feminists describe a number of connections between the twin dominations that are significant in understanding why the environment is a feminist issue and conversely, why feminist issues can be addressed in terms of environmental concerns. The task of feminists is to expose this dualism and the ways in which feminizing nature and naturalizing women has served as justification for the domination of women, animals and the earth. Eco-feminism calls for an end to all oppressions. Its theoretical base is a sense of self most commonly expressed by women and various other non-dominant groups - a self that is interconnected with all life. While analyzing oppression, the socialists, animal liberationists, ecologists, and feminists make the distinction between privileged and oppressed class, where the privileged are the upper or middle-class, technologically and industrially 
developed man and human and the oppressed are the poor or working-class, nonhuman animal, undeveloped nature, and women respectively.

Chodorow (1978) and Gilligan (1993) affirm that a sense of self as separate is more common in men, while an interconnected sense of self is more common in women. Warren (1990) argues that ecofeminism places central values on care, love, trust, and mutual reciprocity. Similarly, Plumwood (1993) maintains that the interconnected self stands in a particular relationship of care, custodianship and friendship. Whether these self-conceptions and affiliated ethical systems are innate or culturally learned is uncertain.

Gilligan opines that while both sexes have the ability to access both types of moral reasoning, the focus phenomenon is particularly gender-based, that is, men tend to focus on rights, whereas women tend to focus on responsibilities. What is certain is that a failure to recognize connections can lead to violence, and a disconnected sense of self is most assuredly at the root of the current ecological crisis. Plumwood (1991) says that the failure of mainstream environmental philosophies, including those based on deep ecology, is derived from the conception of self rationalism. This conception cannot avoid being egoistic because it sees the self against others and does not leave room for essential connection to others. She proposes the conception of interconnected self. It is now common knowledge that rights-based ethics evolve from a sense of self as separate, existing within a society of individuals who must be protected from each other in competing for scarce resources.

In contrast, Gilligan $(1987,23)$ adopts a different approach, more common to women, in which "the moral problem arises from conflicting responsibilities rather than from competing rights and requires for its resolution a mode of thinking that is contextual and narrative rather than formal and abstract. This conception of morality as concerned with the activity of care canters moral development around the understanding of responsibility and relationships, just as the conception of morality as fairness ties moral development to the understanding of rights and rules". Similarly, Warren (1990) puts that "The Power and Promise of 
Ecological Feminism" describes eight boundary conditions of a feminist ethic; that is, conditions within which ethical decision making may be seen as feminist. As Warren argues the boundary conditions are important because they begin to add specific structure and detail to a more pragmatic eco-feminist theory. These conditions include coherence within a given historical and conceptual framework, an understanding of feminism as striving to end all systems of oppression, a pluralistic structure, and an inclusive and contextual framework that values and emphasizes humans in relationships, denies abstract individualism, and provides a guide to action.

The feminist approaches to ethics are distinguished by an explicit commitment to correcting male biases they perceive in traditional ethics, biases that may be manifest in rationalizations of women's subordination, or in disregard for women's moral experience. Feminist ethics begins from the convictions that the subordination of women is morally wrong and that the moral experience of women is as worthy of respect as that of men.

Just as feminist ethics may be identified by its explicit commitment to challenging perceived male bias in ethics, so approaches that do not express such a commitment may be characterized as nonfeminist. Non-feminist approaches to ethics are not necessarily antifeminist or male-biased; they may or may not be so. Whatever else it is, feminism is at least the movement to eradicate sexiest oppression.

Environmental ethics and feminist ethics challenge ethical theory in a number of ways. From the perspective of environmental ethics, one reason why ethical theory is challenged is that environmental ethics belongs to the field of applied ethics. Applied ethics relates ethical theory to practice, which means that our relationships with nature constitute the foundation out of which ethical reflection departs. It also means that ethical theories are applied to these relationships. One way of illustrating these challenges is to look upon environmental ethics as crossing a number of boundaries, which ethical theory traditionally presupposed. One example of such a boundary is the boundary between present and future generations. Another example is that the boundary between what is considered as human and as non-human is crossed as soon as the 
question of non-human carriers of intrinsic value is introduced by non-anthropocentric environmental ethicists. Nature, it is presented, needs to be taken into account on its own merits.

Feminist ethics also challenges ethical theory in several ways. For instance, feminist ethics presupposes that most dominant theories within non-feminist are based on specific assumption about an ideal ethical theory saying that such a theory should be abstract, universal, value-neutral, and objective. Feminist ethics questions these ideals and highlights that they are based on an assumption regarding the possibility to keep reason and emotion apart. That is to say, allegedly emotions are subordinate to reason in nonfeminist ethics. Consequently, feminist ethics suggests that an acceptable ethical theory also ought to consider emotional aspects of moral life.

Feminist ethics also emphasizes that contextual considerations are of importance for decision-making and for ethical theory. This means that we, as ethicists, should pay attention to the relationships of moral agents. One of the reasons why feminist ethics emphasize context is that feminist ethics holds that there is no value neutral theorizing. From the fact that they regard theorizing to be value laden follows that we ought to pay attention to the conditions in which theories and values are developed in order to properly assess whether the theories in question are acceptable. In addition, feminist ethics rejects the idea of either abstract and general normative theories or contextually dependent normative theories. Rather, feminist ethics seeks to reconcile the two from the perspectives of women's everyday life experience (V. Held, 1993).

Thus, feminist ethics highlights the relevance of women's experiences as women for ethical theory. This focus is stressed because feminists regard women to be marginalized in traditional ethical theory. According to feminist ethics, the fact that women constitute a subordinate social group means that the ethical insights drawn from the experiences of women are highly significant. Consequently, feminist ethics highlights relationships in general, and women's relationship in particular as startingpoints for ethical theorizing which is also connected to the claims 
that emotions are "[...] at least a partial basis for morality itself and certainty for moral understanding" (Held, 1993, 52).

In addition, feminist ethics asserts that the public and the private, the personal and the political and therefore also culture and nature are enmeshed in complex relationships and structures, and the claims that the fact that traditional ethical theories have maintained these as separate spheres is of moral as well as of ethical concern. Feminist ethics holds that women have been conceptualized as belonging to what is commonly referred to as private and natural spheres and men to what is referred to as public and cultural spheres. Therefore, women are often regarded to be 'closer to nature' than men. In this view, the meaning of women is enmeshed with or reduced to biological functions (biological essentialism).

Feminist ethics question this oppressive attitude and argue that what is regarded as private actions such as childbearing and breastfeeding have political/cultural as well as private/biological significance. In line with this, feminist ethics also stresses that culture and nature are intertwined in a way that makes dualistic ontology questionable. Furthermore, feminist ethics claims that the fact that what is regarded as a typically female practice is defined as a natural practice follows a lower status of embodied experiences than of a cultural and more abstract practice.

What is more, feminist ethics favours a conception of a social self in contrast to a conception of an isolated self because allegedly individualistic selves do not recognize the importance of relationships. Consequently, a social self is presented as alternative to the purportedly traditional liberal view of the self - a self fundamentally isolated from other selves (V. Held, 1993). The social self is constituted partly or completely in and through its relationships with others.

Eco-feminism entails a variety of theoretical positions that resembles the theoretical variety in non-feminist environmental ethics. The conception of nature and nature's value, social constructivism, ethical contextualism, and ideas of consistent and inconsistent selves identified within eco-feminism can be found in non-feminist environmental ethics as well. Even though there have been different standpoints among the eco-feminists like Warren, 
Merchant, and McFague, they have a common standpoint. On view of nature, eco-feminism emphasizes that nature is active, from which follows that nature ought to be respected. In eco-feminism, nature is represented in "place-oriented" (Ariansen, 1996, 39) and "process-oriented" (Hargove, 1989, 195) views. Although Cuomo's view can be characterized as place-oriented, it combines such a view with a process-oriented view of nature.

The idea that nature indicates a process-oriented view and the conception of ecological communities as composed of eco-systems, populations, and bio-regions implies a place-oriented view (C.J. Cuomo, 1998). According to which "[. . .] the ongoing natural history [. . . ] constitutes the essence of nature" (Hargove, 1989, 195), Cuomo holds that the ongoing area-specific processes of flourishing constitute nature. Merchant's view of nature reflects a general descriptive human/nature dualism that falls outside the different non-feminist views of nature. Here, nature as a whole is distinguished from humanity as a whole. This view presupposes an easily distinguishable separation between the human and nonhuman (Merchant, 1996). According to Merchant, nature is neither essentially a place nor a process. Rather, nature and humanity are viewed as communities, which interrelate as communities.

The fact that eco-feminism regards nature to be an active subject does not mean that nature is viewed as a moral agent, rather, nature in general and particular nature-others are best as moral. This means that ethical standpoints are taken by humans alone regardless of whether humans are essentially natural creatures or not. On concern of values of nature, eco-feminism takes a nonanthropocentric standpoint. This becomes evident since Cuomo, Warren, McFague, and Merchant all share a basic claim that nonhumans have value beyond their utility and external value for humans, which is also one of the central current debated issues of environmental ethics.

Regarding social constructivism, eco-feminism acknowledges the idea of nature-as-it-is as well as the idea that certain aspects of nature-as-it-is such as knowledge, meaning, and physical aspects are products of social processes. Regarding the conceptions of the self, eco-feminism supports the idea that the self is eco-socially constituted and opposes the idea that the human self is externally 
related to other human selves and to non-human others. Ecofeminism advocates a conception of an eco-socially internal self, which implies that we are what and who are through our relationships with others, and, that those who we become are not identical with the whole of which we are parts, or, with the ones to whom we are related.

A materialist analysis indicates that it is rooted in everyday struggle. These academic disciplines are simply tools for explaining the ethical impulse. Environmental ethics and feminist ethics focus on two important social and theoretical issues-the welfare of nonhuman nature and the unequal relationship between men and women respectively. The fact that eco-feminism explicitly combines feminist concerns with nature issues means that eco-feminism is a unique environmental philosophy because it is double natured. This double nature is expressed in the twin domination thesis. For these reasons, it is of importance to analyze central environmental ethical theoretical issues in eco-feminism.

Eco-feminism holds that environmental ethical theory and practice are internally related. This is evident in the different kinds of social constructivism but also in some of the eco-feminist conceptions of value of nature. The philosophical literature on feminism and environmentalism are ethically linked. The claim is that the interconnections with the conceptualizations and treatment of women and nature require a feminist ethical analysis and responses. The goal of feminist environmental ethics is to develop theories and practices concerning humans and the natural environment which are not masculinist and which provide a guide to action in the pre-feminist present (Warren, 1990). In a similar spirit, the understanding made in analyzing the ups and downs of the progress of environmental ethics, perhaps, what is important today for preservation of ecology, is not a movement from theory to practice, but one from practice to theory or more truly enabling practice that theory and practice should develop together.

Ecological feminism is used to refer "to a sensibility, an intimation, that feminist concerns run parallel to, are bound up with, or perhaps, are one with concern for a natural world which has been subjected to much the same abuse and ambivalent behaviour as have women" (Cheney, 1987, 115). Although there are a variety of 
eco-feminist positions (Warren, 1987), the common thread that runs through eco-feminist scholarship is that the domination of women and the domination of nature are "intimately connected and mutually reinforcing" (King, 1989, 18).

The distinctive characteristic of eco-feminist is that it is forced to deal with some of the challenges in environmental ethics in a way that does not allow for definite either or theoretical standpoints, because it dwells on the twin domination thesis. The multifaceted appearance of eco-feminist ethical theory in general can be thus understood as an expression of the combination of concern for nature and feminist concern.

From the observation of the delineated nature and objective of feminist issue, we can ask whether feminist issue is conceptual or not. Unquestionably, the connection between the twin domination is conceptual and also the extension of feminism towards ecofeminism (Warren, 1990). Warren's theory of eco-feminist ethics arises out of a critique of the dominant conceptual framework that underlies Western thought, which is oppressive, because it "functions to explain, maintain, and 'justify' relationships of unjustified domination and subordination" (K. Warren, 2000, 46).

This oppressive conceptual framework rests on "oppositional value dualisms", such as men/women, culture/nature, reason/emotion dichotomies seen as being exclusive and oppositional (Warren, $2000,46)$. If we review the features of an oppressive conceptual framework that Warren has identified, the way that the public/private distinction operates in the abuse of women and environment will become clearer.

The oppressive conceptual framework can be elucidated as the one, which explains, justifies and maintains the relationship of domination and subordination among species of the biotic community, whereas the patriarchal type conceptual is that kind of conceptual oppression, which explains, justifies and maintains the subordination of women by men based on gender bias (Warren, 1990). 
Warren argues that there are three significant unique features of oppressive conceptual framework-value hierarchical, value dualism and logic of domination. The characteristic feature of value hierarchical thinking is giving privileged 'up' over the other 'down'. Thus, for example, human beings enjoy higher value and position than the other species of the biotic community. Men have been seen as being up, so they have been given higher worth than women, who are considered as down. Power and privilege are granted to ups and kept from the downs, which helps the system remain in place.

This logic of domination perpetrated on women and nature results in binary oppositions, dualisms that have come to structure the Western world and Western philosophy. For feminists, as Warren indicates, the dualism of primary concern is that of men/women; for eco-feminists, the human/nature dualism is at issue. Because of this centuries-long construction of the patriarchal, human-cantered world, the work of eco-feminist s consists of conceptualizing these binary dualisms in new ways, to get away from the dominating logics used to naturalize and justify their continued existence. Mere reversal is not enough; the underlying assumptions between them need to be uncovered and examined.

King emphasizes a further dimension of eco-feminism by showing that conceptual eco-feminism is naturally closely aligned with the peace movement and the other struggle to end domination of people as well as nature. She calls eco-feminism as 'cultural feminism', which rejects both the denial of the nature/women link (rationalist feminism). Moreover, she $(1981,15)$ believes that “gender is a meaningful part of a person's identity [. . .]. As women we are naturalized culture in a culture defined against nature. If the nature/culture antagonism is the primary contradiction our time, it is also what weds feminism and ecology and makes women the historic subject. Without an ecological perspective which asserts the interdependence of living things, feminism is disembodied."

Eco-feminism's critique of predominant Western environmental attitudes is at least in part quite like that of deep ecology: the central fault is an attitude, logic and practice of dominating nature. Deep ecology's 'anthropocentrism' and Warren's 'naturism' appear to be same. The central difference between their negative analyses 
seems to be that while deep ecology focuses exclusively on human domination of nature, Eco-feminism insists that a proper analysis must also emphasize the intimate logical and historical connections between the various forms of domination - the same logic and attitudes of superiority and practices of domination humans display in their relations towards the nonhuman dimensions of the world are found in men's relations to women and in imperialistic, racist, and classist structures and practices. Some eco-feminists claim that deep ecologists reveal their male chauvinism when they at most allude to the connections among these various forms of domination.

Eco-feminism emphases that the definition of contextual aspect as individual physical relationship, social structures, individual perspectives and historical processes. The meaning of context as a perspective held by an individual is represented in both ecofeminism and environmental ethics (Callicott, 1999). Warren claims that certain observations, sets of frameworks determine whether certain normative principles are applicable or not. The personal physical relationship between the individual and the nature located in our geographical context and pointed out that we can interrelate (contextualize) with nature in different places (McFague, 1982). According to Cuomo, moral contexualism is focused on socialcultural aspect, in which the contextual aspects are social power structures. This approach is similar to the situation-oriented approach.

As a doubled natured ethical theory, the distinctive characteristic of eco-feminism between nature and culture is expressed in descriptive as well as normative terms. The unique combination of normative feminist and bio-centric and eco-centric claims, calls for full attention to the moral significance of women (humans) as well as for non-humans, simultaneously. In fact, following ecofeminism, the intrinsic value of humans and non-humans in which eco-feminist takes as starting point, cannot be manifested separately. What is more, the eco-feminist social constructivism and descriptive contextualism show how nature is dependent on nature, culture on culture and vice versa. 
In one aspect, eco-feminism sets the ideal that theoretical standpoints ought to be developed in close relationship to different practice. One of the main characteristics of eco-feminism is that theoretical standpoints are not only a matter of general theory acceptance but also a matter of personal moral responsibility. Accordingly, the question concerning which theoretical standpoint that we choose becomes a normative moral matter.

The fact that we have to be personally responsible for our theoretical standpoints is illustrated by the fact that eco-feminism stresses the theoretical as well as the practical consequences of our attitudes against nature. This is further illustrated by the stress on the importance of making a reflected choice to pay attention to nature as subjects of their own worlds. In addition, this is illustrated by the emphasis on the possibility to utilize experiences of being a member of oppressed groups as and to use these experiences as critical perspectives out of which oppressive moral orders and ethical theories can be criticized. Finally, this is also illustrated by eco-feminist individualistic social constructivism.

A new understanding of humanity in the web of life can be built up with the effort to comprehend that men-women, humanity-nature divide is not only the way to construe reality. The account of ecofeminist insight instigates that the men-women divide has led to the exploitation of women and others who were viewed as closer to nature. The perspectives of feminist and environmental ethics seem to bring about the possibility to recover a sense of interdependence of all individuals, human and nature. An eco-feminist ethics involves a reformulation of the concept what it means to be human, and in what human ethical behaviour consists.

The underlying concept of eco-feminism denies abstract individualism. The relationship of humans to the non-human environment can be visualized as constitutive of what it is to be a human, if one tries to understand what eco-feminism is. By making visible the interconnections among the domination of women and nature, eco-feminism shows that both are feminist issues mutually supporting, conceptually linked and that explicit acknowledgement of both is vital to any responsible environmental ethics. 
Eco-feminist philosophy seeks not only to understand the condition of women but also to use that understanding to liberate women and nature from the structures of oppression and logical structure utilized in the justification of domination. Different environmental problems call for different ethical analyses. One thing that speaks in favour of eco-feminist contextualism is that because ecofeminism is rooted in the feminist movement and in feminist ethics, it belongs to an ethical tradition that is used to handle the complex matters that arise as soon as we are trying to construct practical theoretical approaches, such as a practical environmental ethics.

The issues of the view of nature, its value, social constructivism, ethical contextualism and pluralism are also the central issues in environmental ethics. This concludes our reflection on ecofeminism in the present study but its distinctive structure and contribution to environmental ethics may ascertain for further discourse and exploration.

\section{References}

Ariansen, P., The Non-Utility Value of Nature: A Contribution to the Understanding the Value of Biological Diversity, Oslo: Centre for Technology and Culture, 1996.

Callicott, J., Beyond the Land Ethics-More Essays in Environmental Philosophy, New York: Suny Press, 1999.

Cheney, J., "Eco-feminism and Deep Ecology," Environmental Ethic, 9/2 (1987), 115-45.

Chodorow, N., The Reproduction of Mothering: Psychoanalysis and the Sociology of Gender, Berkley: University of California Press, 1978.

Christ, C. P., Rebirth of the Goddess: Finding Meaning in Feminist Spirituality, New York: Routledge, 1998.

Cuomo, C. J., Feminism and Ecological Communities An Ethics of Flourishing, London: Routledge, 1998.

Gilligan, C., "Moral Orientation and Moral Development," in E. Kittay and D. Meyers Women and Moral Theory, Totowa, N.J: Row Man and Allenheld, 1987, 19-33. 
Gilligan, C., In a Different Voice: Psychological Theory and Women's Development, Cambridge: Harvard University Press, 1993.

Griffin, S., Woman and Nature: The Roaring Inside Her. New York: Harper and Row, 1978.

Hargove, E. C., Foundation of Environmental Ethics, New Jersey: Prentice Hall, 1989.

Held, V., Feminist Morality: Transforming Culture, Society, and Politics, Chicago: The University of Chicago Press, 1993.

King, Y., "The Ecology of Feminism and Feminism of Ecology," in J. Plant, ed., Healing the Wounds: The Promise of Eco-feminism, Santacruz: New Society Publishers, 1989, 18-28.

McFague, S., Metaphorical Theology: Models of Gods in Religious Languages, Philadelphia: Fortress Press, 1982.

Merchant, C., Earthcare: Women and the Environment, New York: Routledge, 1996.

Mies, M. and V. Shiva, Eco-feminism, London: University Press Zed Books, 1993.

Ortner, S., "Is Female to Male as Nature is to Culture," in M. Rosaldo and L. Lamphere, eds., Women, Culture and Society, Stanford: Stanford University Press, 1974, 67-87.

Pierce, Jessica, Hilde L. Nelson, and Karen Warren, "Feminist Slants on Nature and Health," Journal of Medical Humanities, 23/1 (2002), 6172.

Plumwood, V., "Nature, Self, and Gender: Feminism, Environmental Philosophy, and the Critique of Rationalism," Hypatia, 6/1(1991), 327.

Plumwood, V., Feminism and the Mastery of Nature, London: Routledge, 1993.

Warren, K., "Feminism and Ecology Making Connections," Environmental Ethics, 9/1 (1987), 3-20.

Warren, K., "The Power and Promise of Ecological Feminism," Environmental Ethics, 17/2 (1990), 125-46.

Warren, K., Eco-feminist Philosophy: A Western Perspective on What it is and Why it Matters, Maryland: Rowman \& Littlefield Publishers, 2000 . 